\title{
ACM and the Professional Programmer
}

\section{In the very early days of computing; professional programming was nearly synonymous with academic research because computers tended to be devices that existed only or largely in}

academic settings. As computers became commercially available, they were found in private sector, business environments. The 1950s and 1960s brought computing in the form of automation and data processing to the private sector and, along with this, a growing community of professionals whose focus on computing was pragmatic and production oriented. Computing was (and is) still evolving and the academic community continued to explore new software and hardware concepts and constructs. New languages were invented (and are still being invented) to try new ideas in the formulation of programs. The introduction of timesharing added new territory to explore and, in today's world, cloud computing. is the new time-sharing, more or less.

ACM was created by the inventors of computing and the focus is clear from the expansion of ACM: Association for Computing Machinery. We are, of course, about 70-plus years into the evolution of computing. ACM is, itself, 67 years old, having been founded in 1947 (I was three years old at the time!). As we look at the landscape today, we see a rich and varied tapestry of software and hardware platforms on and through which computing researchers and professionals pursue their interests. This is not to suggest that researchers are not professionals. Far from it. The point is only that the focus of these groups differs in many respects but may overlap when new processing algorithms are sought and new hardware concepts are needed. Quantum computing, still in its infancy (and maybe in its fantasy), is a case in point where new conceptual algorithms may be needed to take advantage of the unusual computational properties associated with quantum theoretic principles.

It is also worth noting that academic disciplines such as physics, biology, economics, and chemistry are all making increasing use of computing and new algorithms to pursue research and applications. Indeed, the 2013 recipients of the Nobel prize in chemistry ${ }^{a}$ were cited for algorithmic work:

The Nobel Prize in Chemistry 2013 was awarded jointly to Martin Karplus, Michael Levitt and Arieh Warshel "for the development of multiscale models for complex chemical systems."

The question that occupies my mind, especially as the membership in ACM has not grown in a way commensurate with the evident growth of programmers in the profession, is whether and how ACM can adapt its activities and offerings to increase the participation of these professionals. One does not have to be a member of ACM to participate in its many conferences and workshops. One can join a Special Internet Group without being a member of ACM. I would not propose to change any of that. But I

a http://www.nobelprize.org/nobel_prizes/ chemistry/laureates/2013/ wonder whether there are things ACM might do to attract the interest of and, more important, support of professionals who are not researchers in computer science. I think it is even likely the case that not all computer science researchers are members of ACM, in part, for example, because the ACM Digital Library may be available to them through their institutions.

In order to reach the very parties whose opinions and interests I would most like to gauge, this column is being published here and in $A C M$ Queue, an online publication devoted to practitioners.

I would like to ask readers how they satisfy their need to keep informed about computing practices and research results that may influence their own work. Looking back at my own ACM affiliation, which began in 1967 , I was advised by my mentors in graduate school that ACM membership was a mark of a professional and I continue to hold that view. But it seems evident this is opinion not as widespread today. Why not? Is there something ACM should be doing to change that? I would also observe that ACM has an enormous range of activities in education, publications, practices, contests, conferences, and workshops deserving of support from all of us who make our living in the computing space. Perhaps it would be helpful to draw more attention to all of these beneficial activities that are possible only because members and volunteers are committed to them.

I can be reached at vgcerf@gmail.com and I look forward to your perspectives. I

Vint Cerf is vice president and Chief Internet Evangelist at Google. He served as ACM president from 2012-2014.

Copyright held by author. 